\title{
A COMPREHENSIVE ANALYSIS OF VARIOUS TOPOLOGIES OF THE RESONANT CONVERTER
}

\author{
Iqra Jan \\ Research Scholar \\ School of Electronics and Electrical Engineering \\ Lovely Professional University, Punjab, India
}

\begin{abstract}
With the new developments in the field of power electronics, the industrial application demands the usage of power semiconductors with high-frequency switches (IGBT'S, MOSFET's, GTO's) and the usage of highfrequency passive devices which have resulted in the innovation of resonant power converters. These converters give the ability of soft-switching with improved current and voltage waveforms and higher power densities. Their key feature is the high frequency operation of the device with minimal losses and increases efficiency. Besides this, the size, weight and hence the cost of the converter also gets minimized. Comparing with the conventional hard switching devices, the above characteristics have given a path to the soft switching devices for various industrial applications. This paper provides a detailed comparison of various types of resonant converters, their topology with the basic principles, various disadvantages and advantages and choosing the most efficient resonant converter in terms of the various parameters defined.
\end{abstract}

Keywords - Resonant Converter, soft switching, ZVS, ZCS.

\section{INTRODUCTION}

Resonant power converters find their applications in UPS, motor speed control, power grids, solar panels, induction heating, HVDC transmission, etc. For many years PWM inverters have been the main choice of inverters because they have a simple design and a rough nature. But these had the limitations of switching losses and usage of semiconductors devices were of few $\mathrm{kHz}$ while the power rating was of 10 's of thousands of watt (Bellar et al., 1998). In case of a hard switching of a device, there is always an overlapping of current and voltage for a short duration during the transition from turn on to turn off or vice-versa as shown in figure 1. As a result, power is dissipated through the switches which result in damage and switching losses. With the increasing usage of high switching frequency, power losses also increase. Moreover, as visible in the diagram the rate of change of current, as well as the voltage, is stiff i.e. $\frac{d I}{d t}$ and $\frac{d v}{d t}$ is high which develops more switching stresses and hence gets added up in the switching losses. Not only this, but the switching stresses result in EMI i.e. the electromagnetic interference which can be explained as a noise/disturbance in a piece of electrical equipment generated by an external source from rapidly varying electrical currents and voltages that reduces efficiency and quality of a converter. These are the complications encountered in high frequency hard switched converter.

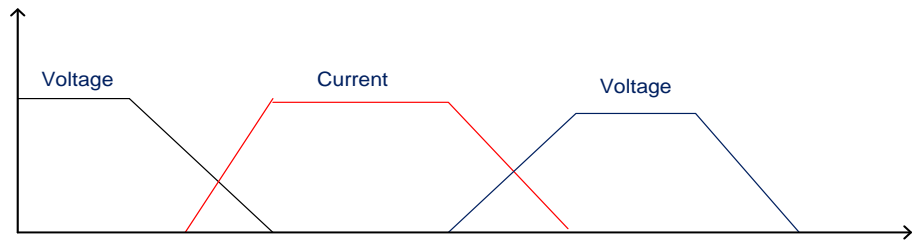

Fig 1. Representation of hard switching in an active switch

More switching losses and reduced efficiency at the areas where the current and voltage overlap can be seen in the figure 1.These limitations could be surpassed with the design of a resonant tank circuit while selecting the proper parameters of various passive components(Resonant Network).This tank works on the principle of resonance which is defined as the condition in an electrical circuit when the electrical energy oscillates between the magnetic field of inductor and the electrical field of capacitor caused at the time when inductive reactance and capacitive reactance are of equal magnitude. In this tank, the current is made to pass through the zero crossing during the switching off and the voltage is made to pass through the zero crossing during switching on time, hence giving the name as zero current switching and zero voltage switching respectively. In other words, the switches are soft commuted in a LC tank i.e. the overlapped area of current and voltage are minimized reducing the losses as shown in Figure 2. Also, $\frac{d I}{d t}$ and $\frac{d v}{d t}$ becomes less reducing the EMI and switching stresses but enduring the quality and efficiency.

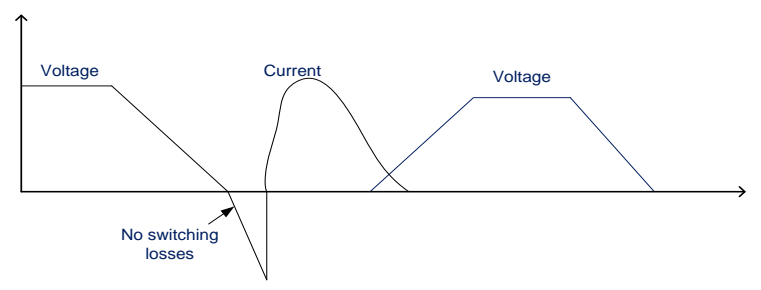

Fig 2. Representation of switching in active switches 
The LC tank needs to be properly configured with optimized value of the parameters. In the upcoming subtopics a proper literature survey is done on the various resonant inverters.

\section{CATEGORIZATION OF RESONANT CONVERTERS}

These resonant converters are actually result of choosing the proper switching arrangement with the defined parameters and synchronizing them with a converter topology that gives a ZVS/ZVC switching (Mohan et al., 1998). Following is a broader way of categorizing the inverter:

\section{A. Load Resonant Converter}

In this case, resonant capacitor $\mathrm{Cr}$ and resonant inductor $\mathrm{Lr}$ are connected in along the load side. The electrical and magnetic energy oscillates between the two elements ( $\mathrm{L}$ and $\mathrm{C}$ ) providing us zero current/voltage switching .In these converter circuit , the power flow to the load is controlled by the resonant tank impedance, which in turn is controlled by the switching frequency $f_{s}$ in comparison to the resonant frequency of the tank $f_{\text {o. }}$

1) Series resonant converter ( $S R C)$ : For a half bridge and full bridge topology of a SLR the basic working principle and waveforms of current and waveform are same. Whenever the normalized frequency fn i.e. fs/fo is between .9090 to .7692 the circuit becomes a capacitive impedance at the load side and switches and diodes undergoes ZCS Low frequency switches like SCR's are used. For high frequency switches BJT's and MOSFET's the circuit changes into an inductive impedance where the fs>fo. SRC find themselves in high switching appliances, not only due to the usage of high frequency switches but also due to the combination of parasites of leakage inductance and switches are added to SRC. The area under the curve gives the region of operation of SRC. The negative slope where fs $>$ fo gives the region where operation is done under ZVS, and for fo $>$ fs the operation is done for ZCS. Because switches like MOSFET's are used for higher frequency applications, ZVS operation is done mostly in these converters.

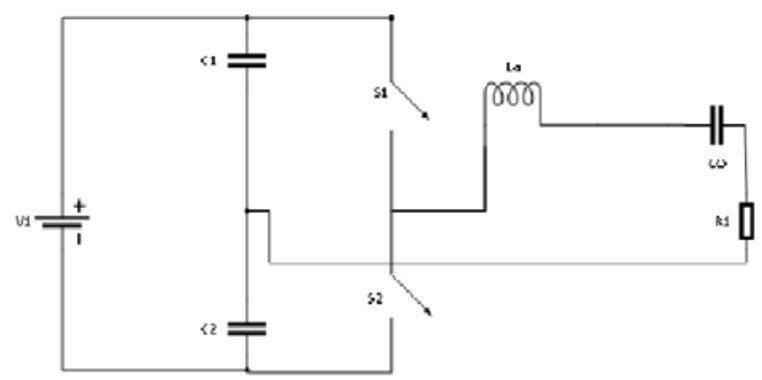

Fig 3. Series connected load resonant converter

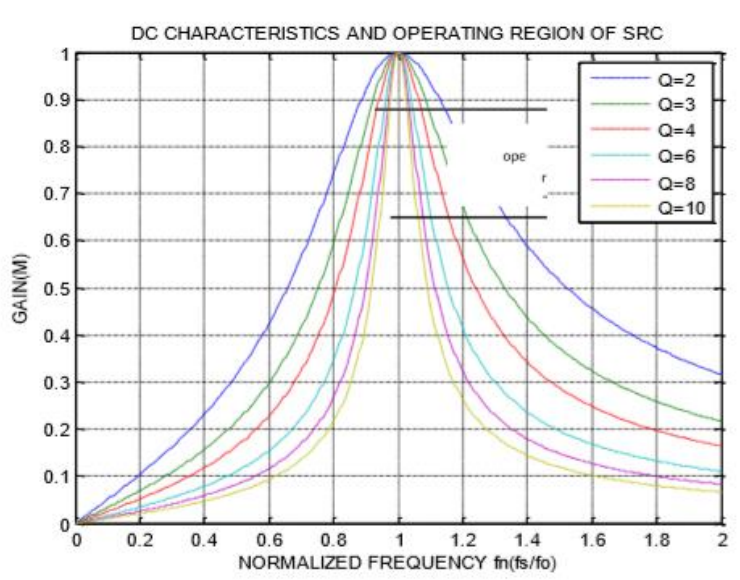

Fig 4 DC Characteristics and operating region of SCR

2) Parallel Resonant Converter (PRC): The $\mathrm{Lr}$ and $\mathrm{Cr}$ are connected in series but the load is placed in parallel with the Cr. Since high frequency voltages pass through the switches like MOSFET's, IGBT's, power BJT's etc. should have the capability of reverse blocking by connecting a diode in series with them. Comparing with dc characteristics of SCR, the graph seen is wider, hence the operating area is decreased.

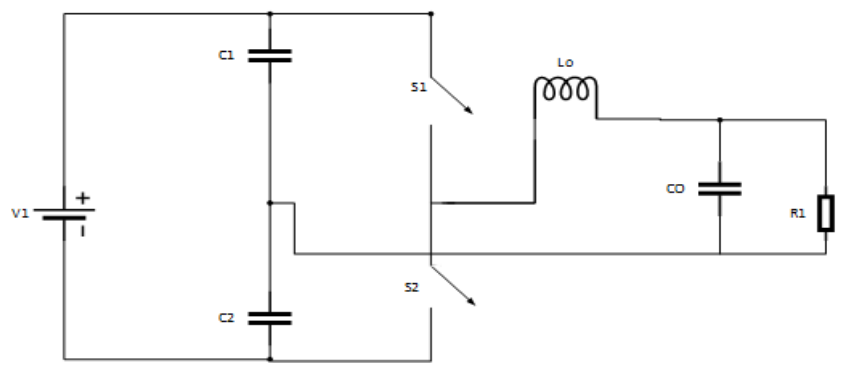

Fig 5. Parallel connected load resonant converter

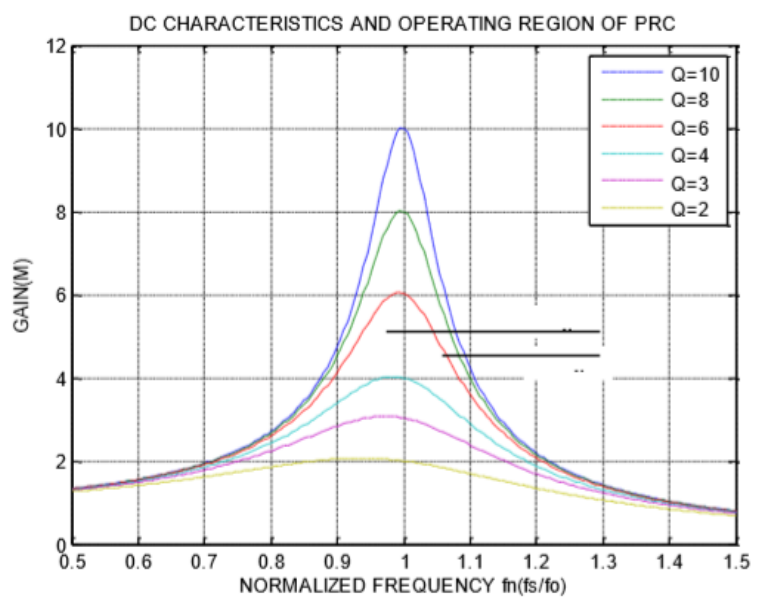

Fig 6. DC Characteristics and operating region of PRC 
Table 1- Comparison between series resonant and parallel resonant Converter

\begin{tabular}{|l|l|}
\hline Series Resonant & \multicolumn{1}{|c|}{ Parallel Resonant } \\
Converter & Circuit \\
\hline $\begin{array}{l}\text { High power applications } \\
\text { 20kHz/10kVA, low distortion, } \\
\text { high efficiency. Applications in } \\
\text { space power conversion, } \\
\text { induction heating, utility line. }\end{array}$ & $\begin{array}{l}\text { industries for induction } \\
\text { heating and metal melting } \\
\text { up to 10kHz. }\end{array}$ \\
\hline $\begin{array}{l}\text { At light loads, to maintain the } \\
\text { regulated output voltage, } \\
\text { switching frequency is } \\
\text { increased and hence output } \\
\text { voltage is regulated. }\end{array}$ & $\begin{array}{l}\text { It acts as voltage source as } \\
\text { the resonant tank and hence } \\
\text { regulation of the output } \\
\text { voltage is not problematic. }\end{array}$ \\
\hline $\begin{array}{l}\text { With increase in input voltage, } \\
\text { the switching frequency } \\
\text { increases, increasing the } \\
\text { impedance, and hence } \\
\text { circulating energy also } \\
\text { increases. }\end{array}$ & $\begin{array}{l}\text { Circulating current is higher } \\
\text { is independent of load. Even } \\
\text { on no load Cr is in parallel } \\
\text { with load and it results in } \\
\text { some impedance giving rise } \\
\text { to some circulating currents. } \\
\text { The losses are same as for } \\
\text { full load. }\end{array}$ \\
$\begin{array}{l}\text { It provides a proper protection } \\
\text { in oase of short circuit } \\
\text { conditions. }\end{array}$ & $\begin{array}{l}\text { More likely to short circuits } \\
\text { because the capacitor is in } \\
\text { parallel with the load. }\end{array}$ \\
\hline
\end{tabular}

3) Series Parallel Resonant Converter: The combination of the series and parallel resonant circuits results in a hybrid resonant circuit where we can use multiple passive components ( $\mathrm{Lr}$ and $\mathrm{Cr}$ ). With this we can have many topologies with an LC circuit called as the multi-resonant circuits. Among these the most common ones are LLC and an LCC circuit. LCC possesses the characteristics of not only commutating the switches like BJT, SCR etc. at switching frequency lesser than the resonant frequency but also it operates the converter at higher frequency switches like MOSFET at ZVS when the switching frequency is greater than the resonant frequency it creates. It increases the efficiency and makes LCC resonant circuit more desirable at higher frequency applications (Yang et al., 1992). Besides this it provides an efficient outcomes for all the voltage and load variations (Deepika et al., 2014)

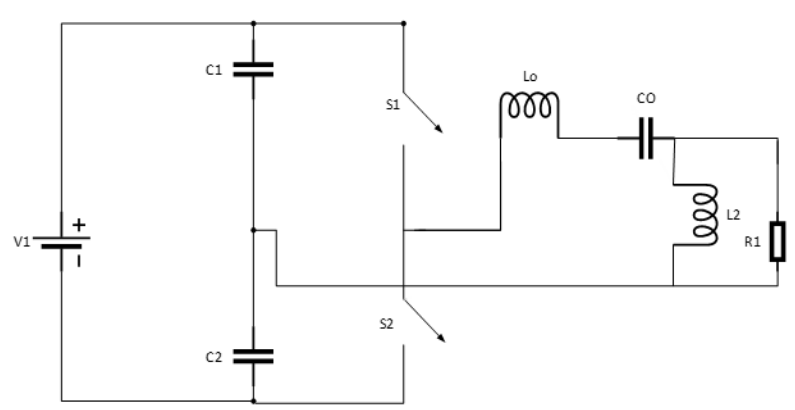

Fig 7. Hybrid connected load resonant converter (LLC)

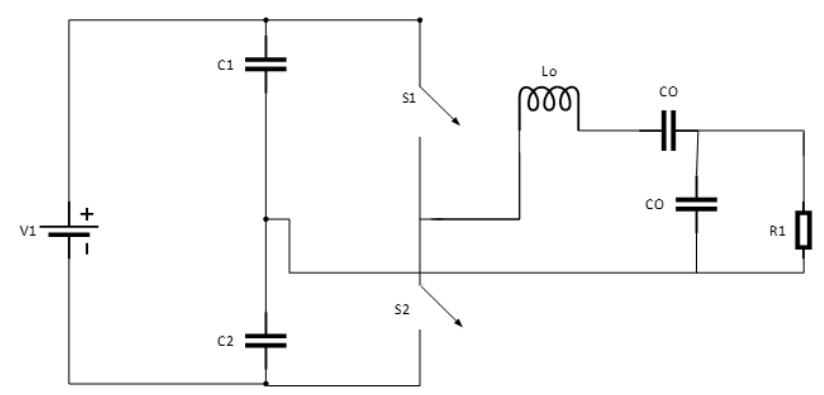

Fig 8. Hybrid connected load resonant converter (LCC)

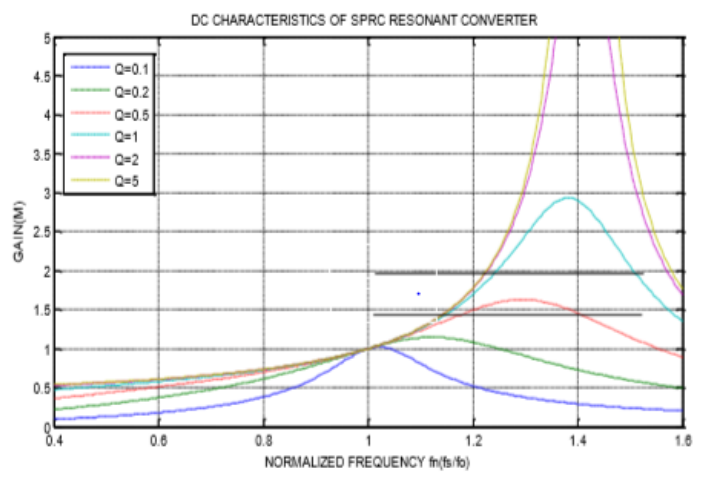

Fig 9. DC Characteristics and operating region of SPRC

\section{B. Resonant Transition Converters}

In this category of resonant converters, in addition to the conventional switches and diodes for the power conversion some another set of auxiliary switches and diodes are used in a half bridge converter. These additional switches and diodes helps in freewheeling of the energy trapped during some free interval in one time period of switching which helps in effective ZVS control of converter during all the transitions of the switch. These are characterized for reducing the switching and the conduction losses[5]. The inductive and capacitive parasites are also added for the effectiveness of ZVS control. 


\section{1) Quasi-Resonant ZVS and ZCS}

The Resonant capacitor provides a zero voltage across switch at the time of turn on and turn off. It is called by this name because the resonance takes place only during the switching and for rest of the interval PWM operation takes place. In case of an ZVS-QR converter the resonant capacitor $\mathrm{Cr}$ are connected across parallel to the switches, and resonant inductor $\mathrm{Lr}$ provides both filtering as well as the resonance. The resonance is obtained by energy oscillating between Lo and Co at the time polarity of pole voltage changes. The resonant inductors are energized by the pole voltage which are measured across the inverter leg and the branch where input voltage is clamped. As a result an alternating current flows through the converter across the switches increases up to 1.5 to 2 times of load current and hence the switching stress is increased (Bellar et al., 1998).It is highly applicable to the areas where higher power applications are required like in audio, switching, power amplification(Tymerski et al., 1990).These converters don't participate in the actual power transfer and hence their size can be customized and the converter can be made compact. Also they are more efficient than the conventional resonant converter and PWM converters (Patterson et al., 1991).

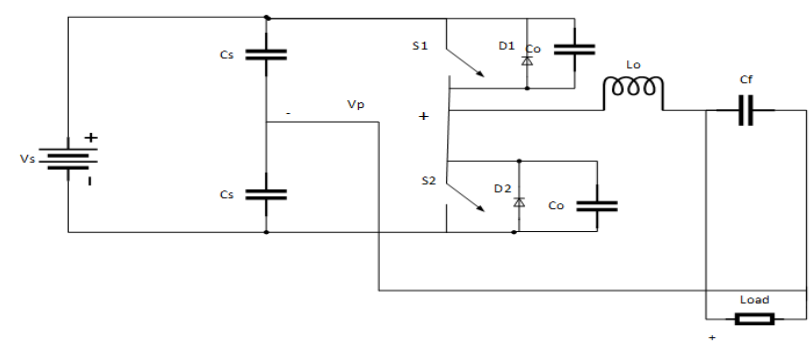

Fig 10. QR ZVS Converter

In order to eliminate the disadvantages of ZVS, we introduce its duality transformation topology called as ZCS-QR. The two switches are connected in series with two resonant inductors and a resonant capacitor is coupled between the two switches. Due to the discharging and charging of this capacitor zero current turn on and turn off are obtained. The most important feature of ZCS is lower current rating across the switches and hence the lower switching stresses. Therefore it is mostly used for higher power and frequency applications. Besides this it has a good application in induction heating and motion control because the capacitor provides an alternating voltage to the loads(Bellar et al., 1998), (Jan et al., 1943).

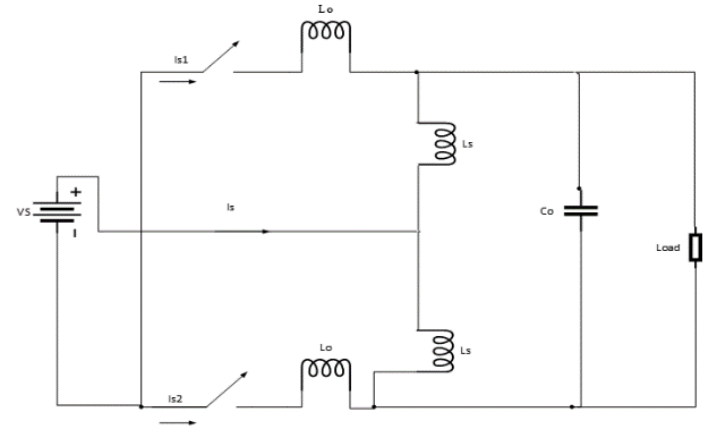

Fig 11. QR ZCS Converter

Table 2- Comparison between QR-ZVS and QR-ZCS

\begin{tabular}{|l|l|}
\hline \multicolumn{1}{|c|}{ QR-ZVS } & \multicolumn{1}{|c|}{ QR-ZCS } \\
\hline $\begin{array}{l}\text { In order to create zero } \\
\text { voltage switching, the } \\
\text { inductive energy much be } \\
\text { high enough to create } \\
\text { resonance with the } \\
\text { capacitor for the active } \\
\text { switches. }\end{array}$ & $\begin{array}{l}\text { In order to create the zero } \\
\text { current switching, the } \\
\text { resonance between the Co } \\
\text { is pross the load whose energy } \\
\text { inductors Ls and Lo occurs } \\
\text { for the active switches. }\end{array}$ \\
\hline $\begin{array}{l}\text { It results in more switching } \\
\text { stress and hence the power } \\
\text { losses are increased. }\end{array}$ & $\begin{array}{l}\text { The important feature in } \\
\text { ZCS-QR is lower current } \\
\text { stress as compared to ZVS- } \\
\text { QR, thereby reducing the } \\
\text { power losses. }\end{array}$ \\
\hline $\begin{array}{l}\text { It is costly and the proper } \\
\text { utilization of the switches } \\
\text { is not acquired. }\end{array}$ & $\begin{array}{l}\text { Despite for the switches to } \\
\text { be at higher voltage rating, } \\
\text { the cost is lesser than the } \\
\text { dual QR- ZVS. }\end{array}$ \\
\hline $\begin{array}{l}\text { It can't withstand high load } \\
\text { variability because at lower } \\
\text { loads the current is less and } \\
\text { hence inductor is not } \\
\text { energized enough to } \\
\text { provide a ZVS. }\end{array}$ & $\begin{array}{l}\text { It does not have the problem } \\
\text { of wide load variations. It is } \\
\text { applicable to high current } \\
\text { applicability as SCR's, } \\
\text { GTO'S. }\end{array}$ \\
\hline
\end{tabular}

\section{1)Resonant Snubber Based DC-AC converter}

For the normal snubbed circuits we use, the high $\frac{d I}{d t}$ and $\frac{d v}{d t}$ across the switch at the time of turn on and off respectively can be eliminated by a series inductor and shunt capacitor connected across it. The consequence is that the energy gets trapped in these elements and results in the losses. The resonant circuit is designed in such a way that at the time of turning on the high switching stress can be eliminated by a series inductor, the energy doesn't get trapped. The resonant converter which 


\section{International Journal of Engineering Applied Sciences and Technology, 2020 \\ Vol. 5, Issue 5, ISSN No. 2455-2143, Pages 184-193 \\ Published Online September 2020 in IJEAST (http://www.ijeast.com)}

provides a parallel path for the current through a thyristor and saves the main circuit from getting the energy trapped and reducing the power losses (Mcmurray et al., 1993).

Basically the auxiliary switches along with the inductor are provided for zero voltage turn on for the main switches and they are zero voltage turned off operating with the capacitor in parallel with switches. (Lai t et al., 1997). The power ratings of auxiliary switches are much lesser than the main switches because they are not concern with the main power flow. Also the main idea is behind the auxiliary switches are to help in resonant energy transferring. The antiparallel diodes have to carry both the currents of load and resonant. During the time when the inductor is discharged which is only a fraction of the switching period reducing the power rating of the diodes. Due to these features, it is one of the highly efficient resonant circuit with high power applications.

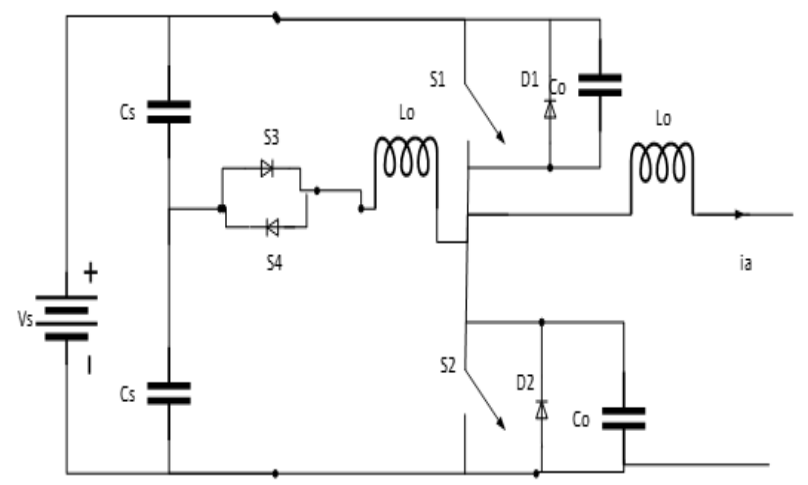

Fig 12. Resonant Snubber circuit

The only main disadvantage encountered is the complexity of circuit due to the added switches and circuits, therby increasing the cost and being more precise on choosing an optimum values for switches.

\section{2) Soft transition resonant converter:}

In the conventional PWM converters, the power flow to the load is directed through the active switches resulting in more voltage and current stresses on them and subsequently higher conduction losses. For a soft transition converter, there is a combination of features of a PWM converter and a resonant converter. During the switch transition, converter uses soft switching techniques while as during other part of the cycle it goes back to the PWM mode. For the previous discussed quasiresonant converters the high frequency operation reduces the switching losses at the cost of increased current and voltage stress which reduces the conduction losses. Here we are representing soft transition converter which uses a parallel auxiliary circuit with the main switches. The main switches operates at ZVS and auxiliary switches at ZCS for both turn on and turn off (Wang et al 2006).
It is divided in two categories:

a) Zero Voltage Transition Converter: Overcoming the disadvantages of QR-ZVS, voltage and the current stress on the main switches as well as the diodes are minimized due to the other path created for the flow of power reducing the overall losses and making it applicable for frequency devices like MOSFET's and IGBT's (Hua et al 1995). The auxiliary switch as visible in the figure activates the smaller resonant circuit and the inductor gives back the energy to the input.

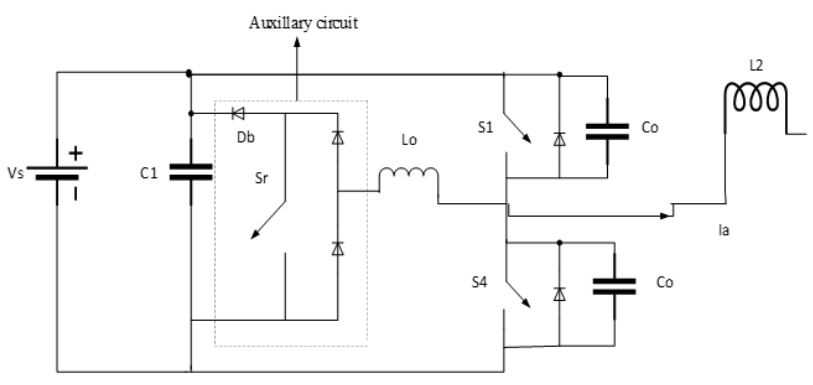

Fig 13. ZVT converter for a single leg

b) Zero Current Transition Converter: Also called as McMurray inverter[1],the resonant circuit provides a ZCS turn on and off of the active switches. The diodes of the main circuit and resonant circuit are operated under hard Switching. The main difference between ZVT and ZCT is that in case of ZVT all the auxiliary switches and diodes undergo ZCS turn on and turn off while in case of ZCT both these undergo hard switching at the load current. The difference is also is their applications. While ZCT is more desirable with the minority carrier switches like IGBT's, BJT's, GTO's etc. and for ZVT it is applicable for power conversion/inversion devices. Now-a-days ZVT used for power factor correction ( $\mathrm{Li}$ et al 1996).

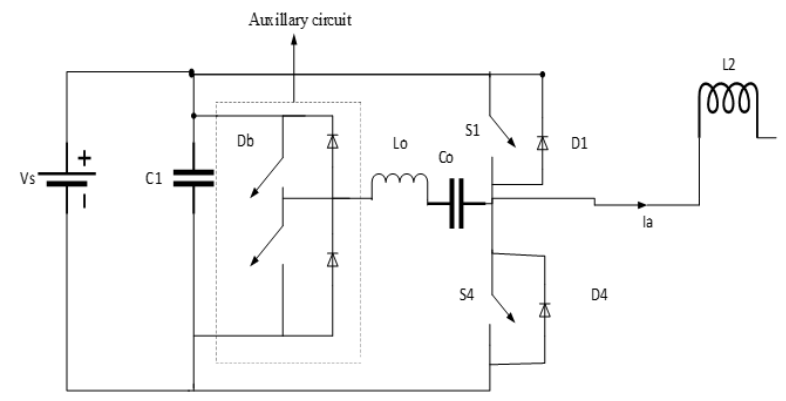

Fig 14. ZCT converter for a single leg

The differences between ZVT and ZCT can be cited as below: 
Table 3- Differences between ZVT and ZCT

\begin{tabular}{|l|l|}
\hline \multicolumn{1}{|c|}{ ZVT } & \multicolumn{1}{|c|}{ ZCT } \\
\hline $\begin{array}{l}\text { Minimal voltage and current } \\
\text { stress reducing the circulating } \\
\text { energy }\end{array}$ & $\begin{array}{l}\text { Reduced voltage and } \\
\text { current stress on the } \\
\text { switches }\end{array}$ \\
\hline $\begin{array}{l}\text { Soft Switching for both } \\
\text { transistor and diodes. }\end{array}$ & $\begin{array}{l}\text { Soft switching for main } \\
\text { switches and hard } \\
\text { switching for auxiliary } \\
\text { switches (ZVS for main } \\
\text { switch and ZCS for } \\
\text { rectifier diode). }\end{array}$ \\
\hline $\begin{array}{l}\text { It is best operated on both low } \\
\text { and full load variations. }\end{array}$ & $\begin{array}{l}\text { Wide line and variations of } \\
\text { load. }\end{array}$ \\
\hline $\begin{array}{l}\text { Hard switching is possible for } \\
\text { auxiliary switch which limits } \\
\text { its usage for high power } \\
\text { appliances[13]. }\end{array}$ & $\begin{array}{l}\text { Hard switching for } \\
\text { rectifier diode. }\end{array}$ \\
\hline
\end{tabular}

C) Resonant Link PWM Inverters: With the conventional resonant PWM converters, we achieve ac voltage by using high frequency switches and reduced conduction and switching losses, while conduction loss are due to the structure of a switch and switching losses are due to high frequency of current ,voltage and switching device (Elmas et al 1994). What we saw in the previous configuration was the power transfers takes place through resistive part of the resonant tank which requires continuous undampenened oscillations. As a result, large VA rating of $\mathrm{LC}$ components and of the switches are required. As a result resonant tank is shifted on dc side as it gets minimally involved in the power transfer (Transaction et al 1989). and provides a link current or link voltage depending on the configuration of the inverter. Not only the losses gets reduced but the power density is also increased. It is categorized in two:

a) Resonant ac link converter: The linked current and voltage are oscillating providing a ZVS/ZVC soft switching. The LC can be inserted in series called as series resonant ac link converter or in parallel called as parallel resonant ac link converter. High frequency link converter find their application in distribution power conversions. In addition to this it reduces the size and weight of the transformer makes converter compact and also reduces the acoustic noise (Sood et al 1998).

1) Parallel resonant ac voltage link converter: The reactive elements Lo and Co are connected in parallel with the converter and the alternating voltage or an oscillating $\mathrm{dc}$ is provided. Bidirectional switches are provided in order to withstand the high alternating voltage. In order to provide zero turn on and off of the switches, ZVS is implemented on the high power devices such as transistors and IGBT's.

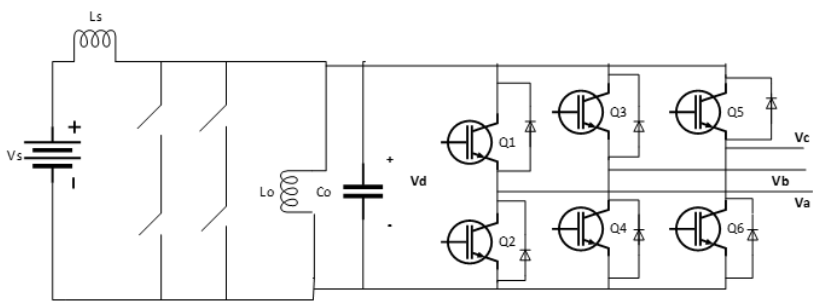

Fig 15. 3 phase parallel resonant AC link converter

2) Series resonant ac voltage link converter: It is duality of the parallel resonant ac link converter. The link current is provided through a rectified dc voltage or simply a battery source by the series connection of Lo and Co. Since this converter provides a ZCS i.e. the switches are turned on and off at the time of zero current, it finds its best application in SCR's because SCR's don't go off until the current goes below the holding current.

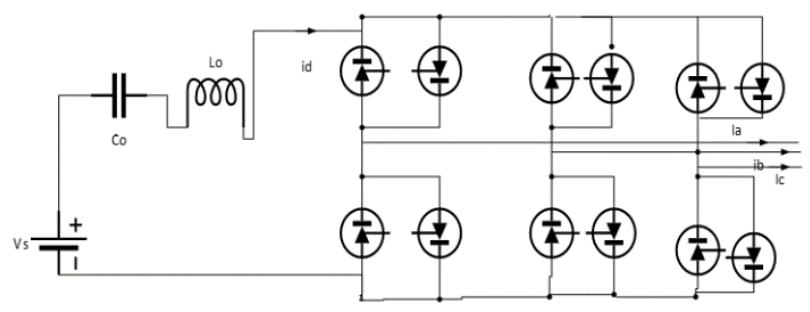

Fig 16. 3 phase series resonant AC link converter

b) Resonant $d c$ link converter: It provides a dc biased oscillating link by a series or parallel connected LC network on the dc side, thereby implementing unidirectional switches in the inverter providing ZVS/ZCS conditions.

1) Parallel Resonant DC-link converter (PRDCLC): As seen in the figure, the dc biased link voltage is provided by the resonating of the components Lo and Co. Therefore the zero voltage soft switching conditions are provided at the zero crossing of the link voltage. One of the disadvantages encountered is that ideally the capacitor is dampened due to the losses in the circuit due to which the soft switching of the converter at zero crossings of link voltage is not achieved. Also there are some overshoot problems with the link voltage. To counter these problems an initial inductor current condition is given by short-circuiting the capacitor and releasing it at the time during the beginning of each cycle so that converter will experience an ZVS. Also the circuit initial conditions will remain same for each cycle. One of the major disadvantages is the voltage stress on active devices is too much as the output rms voltage is merely half of the link voltage. This problem can be overcome by clamping the link voltage to a lower value and also the PWM capability is achieved which can be done with the help of various topologies proposed.[17]. 


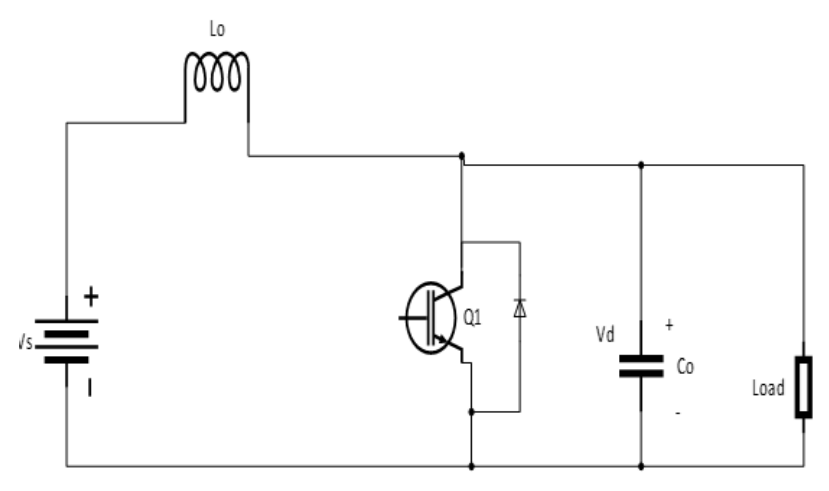

Fig 17. Equivalent diagram of a parallel resonant DC link circuit

Various topologies of PRDCLC are:

1. Actively clamped resonant converter: The voltage stress is reduced to $1.3 \mathrm{~V}$ due to the clamping factor $\mathrm{k}$. The additional clamping capacitor has a value of $\mathrm{Vs}(1-$ $\mathrm{k})$. Yet it has restricted usage due to the pre charging of clamping capacitor.(Transactions et al., 1989)

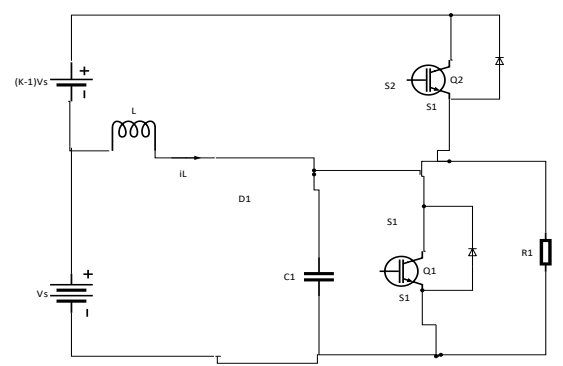

Fig 18. Actively clamped resonant DC link LC converter

2. Passively clamped quasi resonant PWM dc link: There have been many efforts put on the fact that PWM capability should be effectively synchronised with the resonating network. We can improve this by adding auxiliary circuits at the expense of increased conduction losses. Here the clamping of link voltage is provided by inductors and quasi resonant mode is provided by an extra switch. In a new proposed topology (Chen S. et al., 1995) where a magnetic coupling is introduced between two inductors which help is reversing the current during resonant transition eliminating the need of a reverse diode. It even reduces the voltage stress from 2 p.u to 1.1 p.u-1.3 p.u .But these topologies have a problem of minimum intrinsic dwell time due to which they are incapable of providing a proper PWM operation. It can be rectified by introducing a new topology as given in the reference (Filho B.J.C et al 1998).

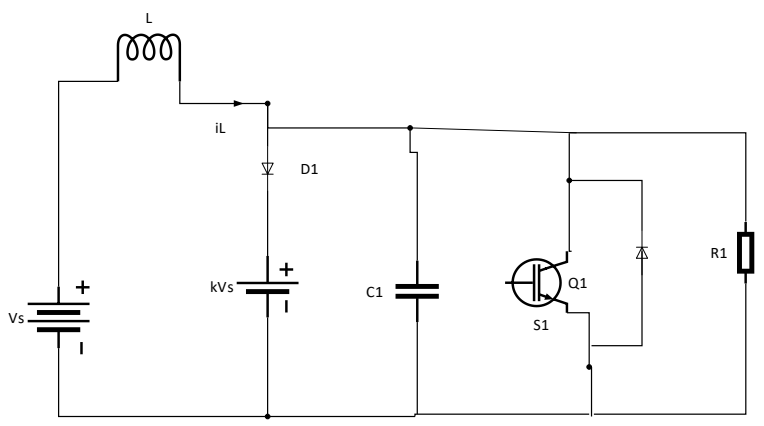

Fig 19. Passively clamped resonant DC link LC converter

3. Quasi-Resonant dc voltage Notch inverter: During the commutation of dc bus, a notch (zero voltage interval) is created, where the soft switching for the inverter is achieved. So the advantage is the notches or the zero crossing interval is optimized with the capability of achieving the precise PWM control. The number of passive elements is decreased and the efficiency and performance is also increased.[20]

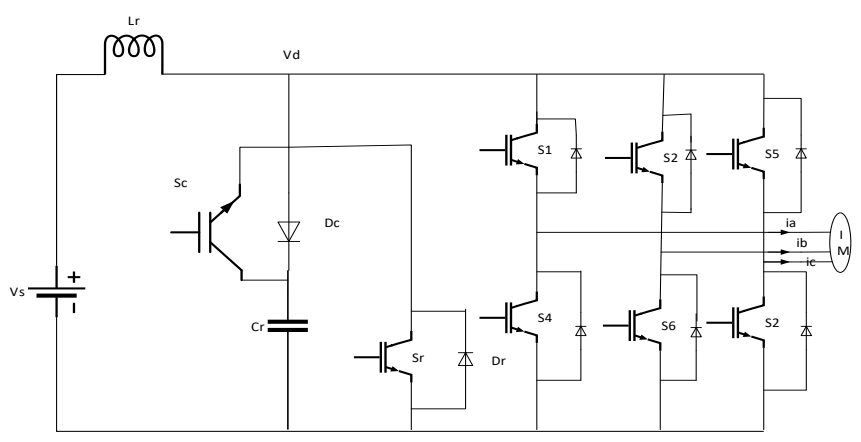

Fig 20. Quasi Resonant Notch Link Converter

2) Series Resonant DC-link Converter (SRDCLC): It is dual of parallel resonant DC-link converter. It provides soft switching by the zero crossing of the link current These find their application in high power, naturally commutated thyristors where the device naturally turns off when the current goes below the holding current like SCR (Murai Y. et al 1992). The disadvantages of this topology is the high link current which can be as high as 6-7 times of load current which needs to be clamped and the proper compatibility with a PWM control strategy just as in dual case of PRDCLC. 


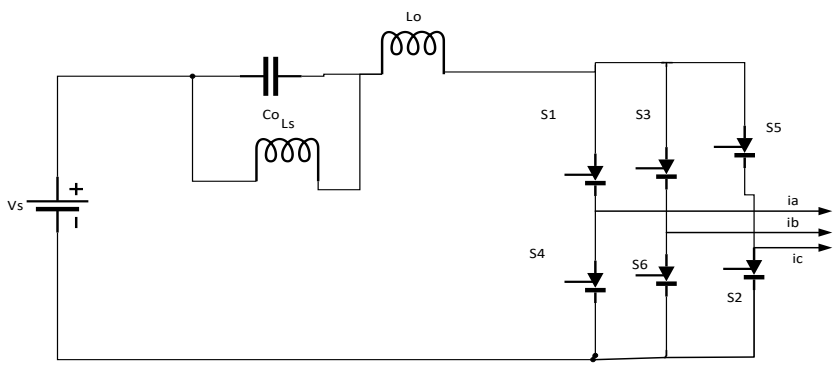

Fig 21. Series Resonant DC link Converter

Some of the topologies of SRDCLC are:

1. Pulse Width Modulated series inverter: In power electronics, Pulse width modulated converters are play in key role in the power conversion process. But in high power applications, the disadvantage of dead time dominates(it is the time when the power flow from the input to the load by the converter is not possible).By proposing this PWM extension of the series resonant converter, the dead time is reduced .Furthermore, a nearly sinusoidal current is achieved and harmonic current is also reduced.[22]

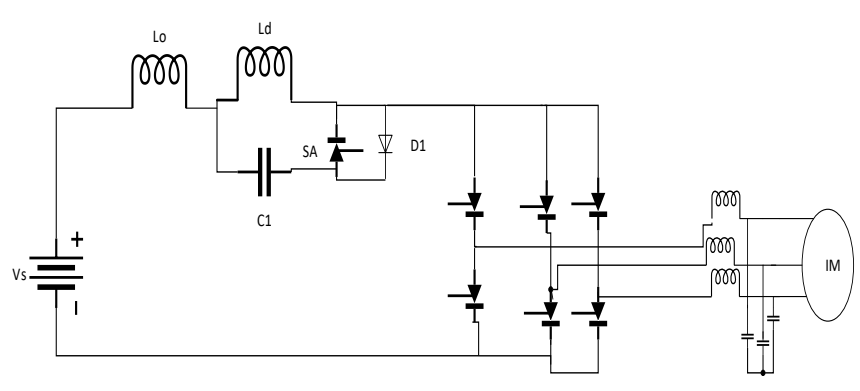

Fig 22. Pulse width modulated Series resonant converter

2. Quasi Resonant DC link Converter: With the development in the resonant converter, through the switching losses are reduced due a great extent but the resonant pulse peak voltage/current is very high than the source voltage/current, thereby converters need a high rating of the switches than the hard switched converters which is quite disadvantageous. Thereby various voltage clamping method are already discussed. In the previous section and for limiting the current, the, methodology introduced here is a storable core for a resonant inductor. Again the problem was the current wave was not flat topped. By introducing a quasi-resonant dc link converter, which not only helps in adjusting the peak value of current also reducing the switching stress. The pulse width can be adjusted and the rating of the switches are also reduced. Due to all this it has more high power applications(Murai Y et al 1993).

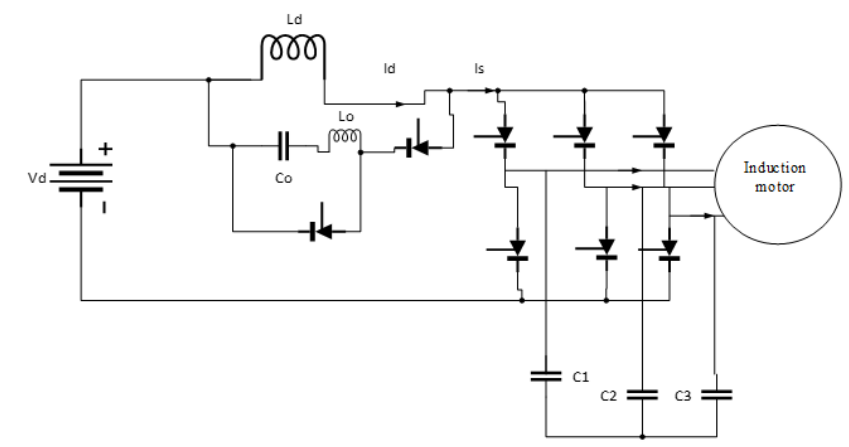

Fig 23. Quasi resonant DC link Series converter

3. Notching current source for soft switching: As we discussed in PDCRC, these notching current converter are developed with a feature of giving a variable flat topped current pulse width and hence decreasing the voltage stress on the active switches. (Silva E.R.C et al., 1994)

\section{CONCLUSION}

With a comprehensive analysis of all the topologies of resonant converters keeping in view various advantages and disadvantages, in order to devise and prototype an optimized topology a combination feature of two things can be considered. A quasi resonant current inverter which forces the active switch to turn on or off at the zero crossing of the current, thus shaping the switch current waveforms and eliminating the switching losses. The resonant pulse that is generated has fixed amplitude and width. When it is incorporated with a notching circuit, the notches can be generated with a desired width and at any instant of time with a PWM technique present. There are various topologies that help us attaining the notching current. The auxiliary commutation circuit introduced in the topology diverts the path of the dc link current and hence creating notches in the link current.

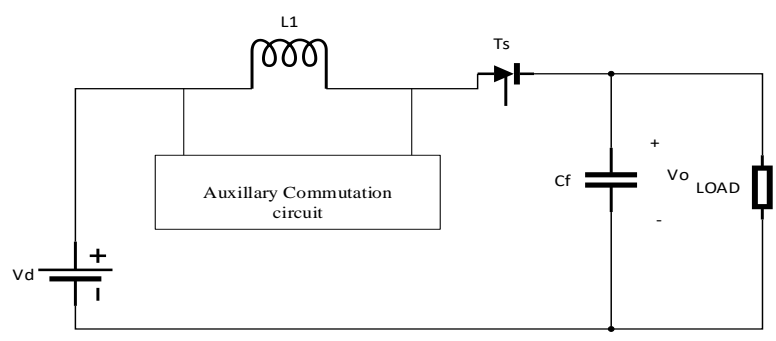

Fig 24. Equivalent Circuit of Notching Current source Inverter 


\section{International Journal of Engineering Applied Sciences and Technology, 2020 \\ Vol. 5, Issue 5, ISSN No. 2455-2143, Pages 184-193 \\ Published Online September 2020 in IJEAST (http://www.ijeast.com)}

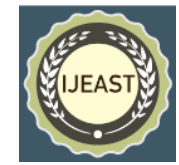

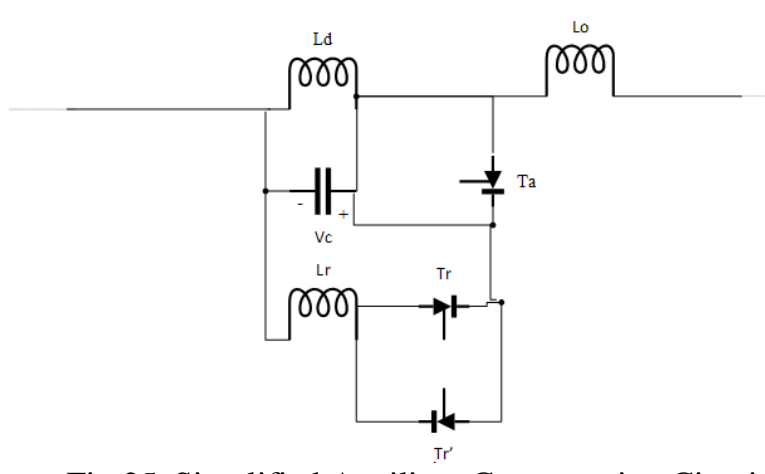

Fig 25. Simplified Auxiliary Commutation Circuit

After looking into the various factors like circuit simplicity of the network, lesser usage of inductors and capacitors and most importantly helping us to eliminating the switching losses by creating the notches at the desired points with a desired width, the above auxiliary circuit is the most simplified one which would precisely meet the demand required by a resonant circuit.

\section{ACKNOWLEDGEMENTS}

I would like to acknowledge Lovely Professional University and my lectures Mr. R K Sharma and Sateesh Reddy who guided me throughout the whole process.

\section{REFERENCES}

[1] Bellar M.D.,Wu T.S., Tchamdjou A., Mahdavi J., and Ehsani M. (1998),.A review of soft-switched DC-AC converters," IEEE Trans. Ind. Appl., vol. 34, no. 4, pp. 847-860.

[2] Mohan N., Undeland T.M., and Robbins W.P.,(1998), Power Electronics converters, Applications, and Design, Second edi., S. M. Elliot, S. Culhane, and S. Amanatidis, Eds. Singapore: John Wiley \& sons, pp. 249-295.

[3] Yang E.X.,Lee F.C., and Jovanovic M.M,(1992),Small-signal modeling of lcc resonant converter, pp. 941-948.

[4] Deepika G. and Elakkiya M.,(2014),Comparison of LLC and LCC Resonant Converter Using Conventional and FUZZY, vol. III, no. X, pp. 122-127

[5] Swaminathan B. and Ramanarayanan V., A Novel Resonant Transition Half-Bridge Converter, pp. 17821789 .

[6] Tymerski R., Vorperian V., and Lee F. C., (1990),DCto-AC inversion using quasi-resonant techniques, Midwest Symp. Circuits Syst., vol. 4, no. 4, pp. 527530.
[7] Patterson O.D. and Divan D.M.(1991),PseudoResonant Full Bridge DC/DC Converter, IEEE Trans. Power Electron., vol. 6, no. 4, pp. 671-678 .

[8] Jan P., (1943),Power Conversion using Zero Current Soft Switching," vol. 12, no. 19, pp. 2-4.

[9] Mcmurray W.(1993), Resonant Snubbers with Auxiliary Switches, vol. 29, no. 2, pp. 355-362.

[10] Lai J. and Member S. (1997), Resonant Snubber-Based Soft-Switching Inverters for Electric Propulsion Drives, vol. 44, no. 1, pp. 71-8.

[11] Wang C. M.(2006),Novel zero-voltage-transition PWM DC - DC converters, IEEE Trans. Ind. Electron., vol. 53, no. 1, pp. 254-262.

[12] Hua G. and Lee F.C.(1995), Soft-Switching Techniques in PWM Converters, vol. 42, no. 6, pp. 595-603.

[13] Li Q., Zhou X., and Lee F.C(1996), Novel ZVT threephase rectifier/inverter with reduced auxiliary switch stresses and losses," PESC Rec. - IEEE Annu. Power Electron. Spec. Conf., vol. 1, pp. 153-158.

[14] Elmas C., Bal G.,Colak I., and Coskun I.(1994), High Frequency Resonant DC Link PWM converter," pp. 1251-1254.

[15] Transactions I. and Industry O.N.(1989), ZeroSwitching-Loss Inverters for High-Power Applications, vol. 25 , no. 4 , pp. 634-643.

[16] Sood P.K (1998), Power Conversion Distribution System Using a High-Frequency AC Link, IEEE Trans. Ind. Appl., vol. 24, no. 2, pp. 288-300.

[17] Lipo T. A., Resonant Link Converters: A new direction in solid state power conversion. pp. 0-11.

[18] Chen S. and Lip T. A.(1995), Soft-S witched Inverter for Electric Vehicle Drives Shaotang, pp. 586-591.

[19] Filho B.J.C and Lipo T.A (1998), Space-Vector Analysis and Modulation Issues of Passively Clamped Quasi-Resonant Inverters, vol. 34, no. 4, pp. 861-869.

[20] Lai J. and Electronics P.,High frequency quasiresonant dc voltage notching inverter for ac motor drives' no. 1, pp. 1202-1207.

[21] Murai Y. and Lipo T.A (1992), High-Frequency Series-Resonant dc Link Power Conversion,IEEE Trans. Ind. Appl., vol. 28, no. 6, pp. 1277-1285.

[22] Dasilva E., Grande C., Ledwich G.,Lip T.A., and Wi M., PULSE WIDTH MODULATED SERIES RESONANT CONVERTER, pp. 744-749. 
International Journal of Engineering Applied Sciences and Technology, 2020

Vol. 5, Issue 5, ISSN No. 2455-2143, Pages 184-193

Published Online September 2020 in IJEAST (http://www.ijeast.com)

[23] Murai Y. and Lip T.A.(1993), Quasi Current Resonant DC Link AC/AC Converter, pp. 0-5.

[24] Silva E.R.C (1994), Notching current source AC/AC converters for sofr switched PWM, pp. 1001-1007. 